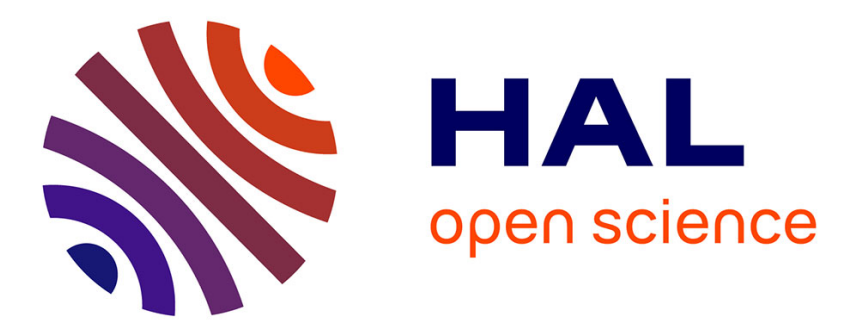

\title{
New In Situ Imaging-Based Methodology to Identify the Material Constitutive Model Coefficients in Metal Cutting Process
}

\author{
Xiao-Ming Zhang, Ke Zhang, Dong Zhang, José Outeiro, Han Ding
}

\section{To cite this version:}

Xiao-Ming Zhang, Ke Zhang, Dong Zhang, José Outeiro, Han Ding. New In Situ Imaging-Based Methodology to Identify the Material Constitutive Model Coefficients in Metal Cutting Process. Journal of Manufacturing Science and Engineering, 2019, 141 (10), pp.101007-1 to 101007-11. $10.1115 / 1.4044251$. hal-02502663

\section{HAL Id: hal-02502663 \\ https://hal.science/hal-02502663}

Submitted on 9 Mar 2020

HAL is a multi-disciplinary open access archive for the deposit and dissemination of scientific research documents, whether they are published or not. The documents may come from teaching and research institutions in France or abroad, or from public or private research centers.
L'archive ouverte pluridisciplinaire HAL, est destinée au dépôt et à la diffusion de documents scientifiques de niveau recherche, publiés ou non, émanant des établissements d'enseignement et de recherche français ou étrangers, des laboratoires publics ou privés. 


\author{
Xiao-Ming Zhang ${ }^{1}$ \\ State Key Laboratory of Digital Manufacturing \\ Equipment and Technology, \\ Huazhong University of Science and Technology, \\ Wuhan 430074, China \\ e-mails: cheungxm@hust.edu.cn; \\ zhangxm.duyi@gmail.com \\ Ke Zhang \\ State Key Laboratory of Digital Manufacturing \\ Equipment and Technology, \\ Huazhong University of Science and Technology, \\ Wuhan 430074, China \\ e-mail: hustzk@hust.edu.cn \\ Dong Zhang \\ State Key Laboratory of Digital Manufacturing \\ Equipment and Technology, \\ Huazhong University of Science and Technology, \\ Wuhan 430074, China \\ e-mail: zhangdong@hust.edu.cn \\ Jose Outeiro \\ LaBoMaP Laboratory, \\ Arts et Metiers ParisTech, \\ F-71250 Cluny, France \\ e-mail: jose.outeiro@ensam.eu \\ Han Ding \\ State Key Laboratory of Digital Manufacturing \\ Equipment and Technology, \\ Huazhong University of Science and Technology, \\ Wuhan 430074, China \\ e-mail: cheungxm@gmail.com
}

\section{New In Situ Imaging-Based Methodology to Identify the Material Constitutive Model Coefficients in Metal Cutting Process}

A great challenge of metal cutting modeling is the ability of the material constitutive model to describe the mechanical behavior of the work material under the deformation conditions that characterizes this process. In particular, metal cutting generates a large range of state of stresses, as well as strains and strain rates higher than those generated by conventional mechanical tests, including the Split-Hopkinson pressure bar tests. A new hybrid analyticalexperimental methodology to identify the material constitutive model coefficients is proposed. This methodology is based on an in situ high-resolution imaging and digital image correlation (DIC) technique, coupled with an analytical model of orthogonal cutting. This methodology is particularly suitable for the identification of the constitutive model coefficients at strains and strain rates higher than those found in mechanical tests. Orthogonal cutting tests of nickel aluminum bronze alloy are performed to obtain the strains and strain rates fields in the cutting zone, using DIC technique. Shear forces derived from stress integrations are matched to the measured ones. Then, the constitutive model coefficients can be determined, which is performed by solving a sequential optimization problem. Verifications are made by comparing the strain, strain rate, and temperature fields of cutting zone from experiments against those obtained by finite element simulations using the identified material constitutive model coefficients as input.

[DOI: $10.1115 / 1.4044251]$

Keywords: metal cutting, material constitutive model, digital image correlation, strain and strain rate, inspection and quality control, machining processes

\section{Introduction}

A direct measurement of the strain and strain rate in metal cutting and thus describe the material behavior remains still a challenge. This paper is motivated by the requirements to provide the material constitutive models for metal cutting process, in which the strain may reach 1-2 and the strain rate up to $10^{5} \mathrm{~s}^{-1}$. Unfortunately, this task cannot be fulfilled by the conventional Split-Hopkinson pressure bar (SHPB) tests, because the strain and strain rates covered by SHPB are lower to those usually found in metal cutting process.

SHPB test is used to get the material response at high strain rates used for the identification of the constitutive model coefficients in a straightforward way. Although a series of modified SHPB apparatus had been developed [1-3], they still generated considerably low strain and strain rate levels.

To overcome the limitations inherited in the SHPB tests, metal cutting tests had been used to generate a broad range of strains and strain rates. Shatla et al. [4] and Sartkulvanich et al. [5] used the orthogonal slot milling to calculate the stress, strain, strain rate, and temperature in the primary shear zone. Then, constitutive model coefficients were iteratively obtained by matching the predicted forces calculated by OXCUT (a computer code developed by the authors) with those measured. By using similar procedure, Özel [6] obtained the constitutive model coefficients by matching the predicted forces obtained from finite element simulations with

${ }^{1}$ Corresponding author.

Manuscript received December 27, 2018; final manuscript received July 1, 2019; published online August 1, 2019. Assoc. Editor: Radu Pavel. those measured in orthogonal cutting. Tounsi et al. [7] identified the constitutive model coefficients based on the piecewise linear distribution of the strain rate and hence obtained sufficient number of the constitutive quantities to fully identify constitutive model coefficients using only one cutting test. Shi et al. [8,9] presented a systematic approach for the identification of constitutive model coefficients through metal cutting tests. They developed a new distributed primary zone deformation model to describe the distributions of the effective stress, strain, strain rate, and temperature in the primary shear zone. The generated constitutive model coefficients were compared with the experimental results. These studies based on metal cutting tests can be called the indirect method, because the strain and strain rate in the primary shear zone were obtained using the Oxley's predictive model [10], rather than direct measurements. The indirect method is accomplished by matching the forces calculated from the predicted strain and strain rate, with those measured in metal cutting tests. Unfortunately, these predicted strain and strain rates are lacking experimental validation.

The following conclusion can be drawn from the above critical literature review on the material constitutive model coefficients identification:

(a) SHPB tests can be used to obtain the constitutive model coefficients in a straightforward way, but they cannot fully cover the range of state of stresses, as well as the strain and strain rate levels generated by metal cutting.

(b) Cutting tests can be an effective way to obtain the constitutive model coefficients, but the combination with theoretical models used to obtain the strain and strain rate distributions lacks experimental verification. 
This paper presents an innovative approach to identify the constitutive model coefficients from orthogonal cutting tests. This approach takes into account the previous work carried out by the authors [11-16] and other works found in the literature [17-20] on the study of the orthogonal cutting process, using digital image correlation (DIC) or particle image velocimetry techniques. It is characterized by the following steps:

(1) Development of an in situ imaging setup, in which highspeed filming of the cutting process and forces recording is performed simultaneously.

(2) Application of the DIC technique to calculate the strain, strain rate, and the stress distributions in the primary shear zone in orthogonal cutting process.

(3) Calculation of the forces by integrating the stresses in the primary shear zone and compare them with the experimental measured ones. A numerical formulation is presented to identify the coefficients of the Johnson-Cook (J-C) constitutive model.

\section{Problem Definition}

$\mathrm{J}$-C constitutive model is adopted here to demonstrate the proposed approach for the nickel aluminum bronze (NAB) alloy, but any other constitutive model can be used, providing that these models are a function of the strain, strain rate, and temperature. $\mathrm{J}-\mathrm{C}$ constitutive model is used widely in the cutting process simulation due to its mathematical simplicity and availability in most of the finite element method software. It is represented by the following equation:

$$
\sigma=\left(A+B \varepsilon^{n}\right)\left(1+C \ln \frac{\dot{\varepsilon}}{\dot{\varepsilon}_{0}}\right)\left[1-\left(\frac{T-T_{0}}{T_{m}-T_{0}}\right)^{m}\right]
$$

where $A, B, C, n$, and $m$ are the yield strength, strain hardening modulus, strain rate hardening coefficient, strain hardening exponent, and thermal softening exponent, respectively. In addition, $\sigma$, $\varepsilon, \dot{\varepsilon}$, and $T$ represent flow stress, effective strain, effective strain rate, and temperature, respectively, while $\dot{\varepsilon}_{0}, T_{0}$, and $T_{m}$ represent the reference strain rate (selected as $10^{-3} \mathrm{~s}^{-1}$ ), room temperature, and melting temperature $\left(T_{m}=1058^{\circ} \mathrm{C}\right)$, respectively.
Our objective is to identify the constitutive coefficients $A, B, C, n$, and $m$. In case of quasi-static (QS) condition, i.e., $\dot{\varepsilon}=\dot{\varepsilon}_{0}$ and $T=T_{0}$, Eq. (1) degenerates to $\sigma=A+B \varepsilon^{n}$. The constitutive constants $A, B$, and $n$ can be identified from the QS compression tests in a standard and straightforward way. Then, we focus on the identification of constitutive model constants $C$ and $m$, which will be realized through experimental determined strain and stain rate, arising in Eq. (1) using DIC analysis and cutting force measurements.

\section{Experimental Studies}

This section presents the experimental setup for the orthogonal cutting tests and the corresponding work material and machining conditions.

3.1 Experimental Setup. Figure 1 shows the experimental setup used in the present study. Orthogonal cutting tests are performed on a computerized numerical control (CNC) turning machine equipped with an imaging system to obtain high-resolution pictures in the cutting process. The workpiece clamped to the spindle and the cutting tool is installed on a piezoelectric dynamometer, Kistler 9257B, for forces measurement. A double-shutter camera coupled to a Navitar X12 zoom lens system is fixed on the machine tool $x$-axis carriage to observe the side surface of workpieces. The magnification factor of the lens could be varied from one to seven. Two fully diode pumped Nd:YAG lasers are used to illuminate the scene with the adjustable interval time $t_{\text {int }}$. The lasers generate two pulses with a $532 \mathrm{~nm}$ wavelength and energy of $10 \mathrm{~mJ}$ sequentially. The duration for each pulse is $5-8 \mathrm{~ns}$, which represents the effective exposure time of the camera. The interval time $t_{\text {int }}$ could be adjusted through the digital delay pulse generator, which is in turn activated by a synchronous trigger.

3.2 Work Material and Machining Conditions. The NAB presents superior properties of high strength, excellent wear, and stress corrosion resistances, which make it extensively used in marine propellers manufacturing. The chemical composition is shown in Table 1.

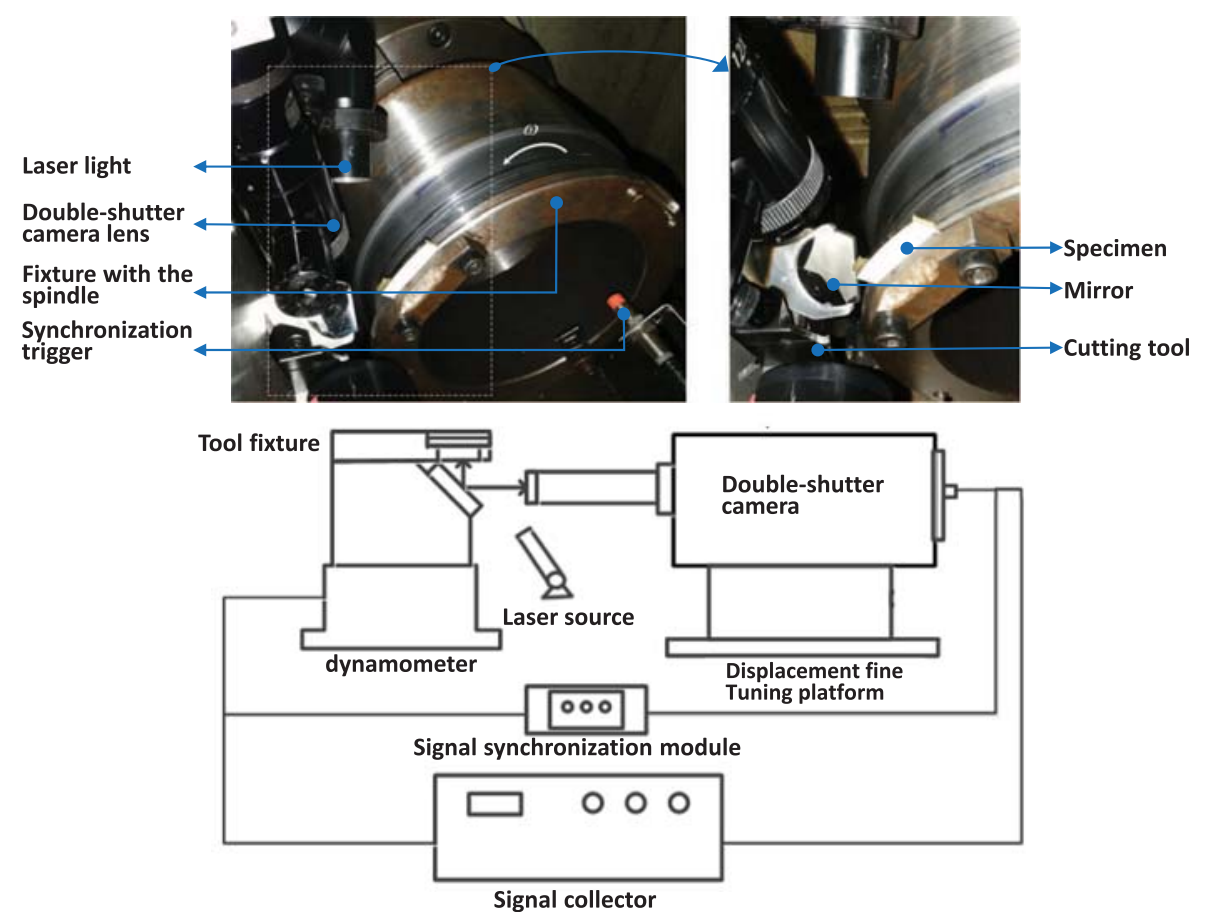

Fig. 1 Experimental setup 
Table 1 Chemical composition of the used nickel aluminum bronze alloy

\begin{tabular}{lccccccc}
\hline \hline Element & $\mathrm{Cu}$ & $\mathrm{Al}$ & $\mathrm{Fe}$ & $\mathrm{Ni}$ & $\mathrm{Mn}$ & $\mathrm{Zn}$ & $\mathrm{Sn}$ \\
\hline Content (\%) & 80.30 & 9.28 & 4.45 & 4.24 & 1.42 & 0.0076 \\
Standard value (\%) & $77-82$ & $7-11$ & $2-6$ & $3-6$ & $0.5-4$ & 0.011 \\
\hline \hline
\end{tabular}

NAB specimens of $40 \times 20 \times 2.5 \mathrm{~mm}$ are fabricated from the bulk material by wire electrical discharge machining. In order to avoid the uneven cutting depth, the samples should be precut, and the geometry is given on the left of Fig. 2, where $T$ and $C$ are the directions of thrust and tangential cutting forces, respectively. The 220 -grit Struers ${ }^{\circledR}$ diamond disc is used to grind the samples, followed by 320-grit microglass sand blasting to produce random speckles (required surface pattern for DIC) on the surface for observation, resulting in better accuracy in the subsequent imaging processing.

Carbide tools with large rake angles are selected to produce continuous chips. The cutting conditions including uncut chip thickness $h$, cutting speed $V$, cutting width $w$, tool rake angle $\gamma$, and clearance angle $\alpha$ are given in Table 2. A series of cutting speeds are set from $30 \mathrm{~m} / \mathrm{min}$ to $180 \mathrm{~m} / \mathrm{min}$. Considering the size of the camera's field of view and the clarity of images, an uncut chip thickness of $0.1 \mathrm{~mm}$ and $0.15 \mathrm{~mm}$ are selected. All the cutting tests are performed under dry cutting conditions.

\section{Strain and Strain Rate Fields in Cutting Zone}

Displacement or velocity fields of the workpiece side surface are measured using the double-shutter camera and further processed by DIC techniques to get the strain and strain rate fields. DIC is a fullfield image processing approach, based on gray value digital images, that can determine the displacements of an object under various working loads, like workpiece deformation in cutting operations. Finite element simulations had shown that the deformation

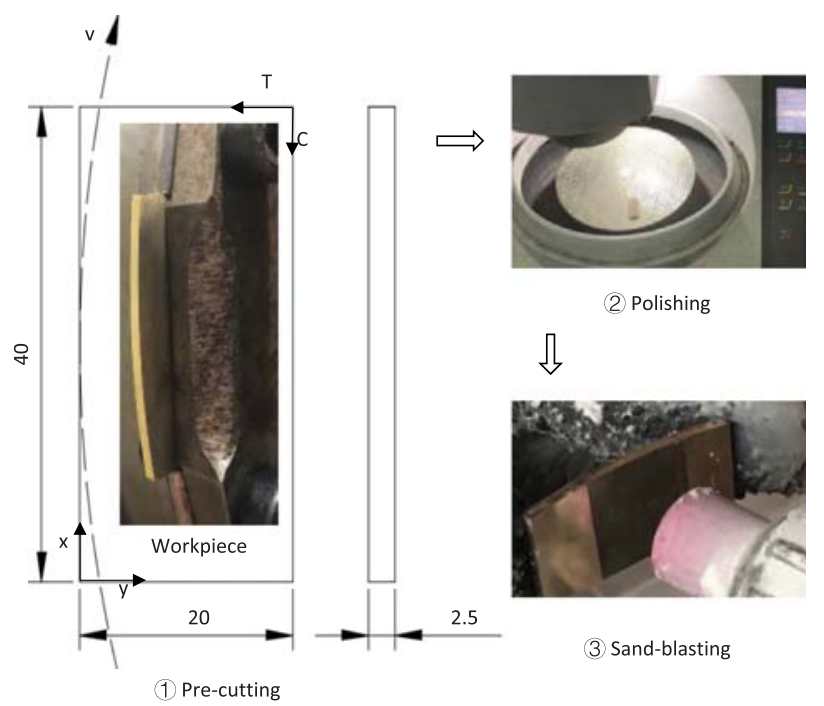

Fig. 2 Specimen preparation: (1) precutting, (2) polishing, and (3) sand blasting

Table 2 Orthogonal cutting conditions

\begin{tabular}{lcc}
\hline \hline Cutting parameters & $h(\mathrm{~mm})$ & $0.1(\mathrm{i}), 0.15$ (ii) \\
& $V(\mathrm{~m} / \mathrm{min})$ & $30(\mathrm{I}), 60(\mathrm{II}), 90(\mathrm{III})$, \\
& $w(\mathrm{~mm})$ & $120(\mathrm{IV}), 150(\mathrm{~V}), 180(\mathrm{VI})$ \\
& $\gamma(\mathrm{deg})$ & 32 \\
Tool geometry & $\alpha(\mathrm{deg})$ & 6.5 \\
\hline
\end{tabular}

in the primary shear zone of the side surface was more similar to plane strain deformation than the plane stress deformation [21]. Therefore, the measured kinematic fields of the side surface are used for analysis.

In the case of 2D, a planar surface is in direct observation by a CCD or CMOS camera with a magnification lens. In this study, the double-shutter camera enables very high-speed imaging with the help of pulsed laser lighting (Fig. 1). The series of images of the specimen surface are recorded, digitized, and stored as digital images during the cutting process. The two images recorded in adjustable interval time $t_{\text {int }}$ are compared to determine the displacements $(u, v)$ by searching a matched point $(x, y)$ in the deformed image to one $(X, Y)$ in the reference image, also called pixel registration. Initially, digital images are divided into small regions, i.e., the subsets with multiple pixel points $(40 \times 40$ pixels in this study), which are used to perform the matching process. The subset is also called correlation window, which has a unique light intensity (gray level) distribution, which is assumed to be constant during the deformation process. The displacement of the correlation window on the reference image is tracked by searching the subset with the same light intensity distribution in the next image. Once the correlation window location in the deformed image is found, the displacement and velocity can be determined. This process is repeated until the displacement field of all the pixels are obtained. Mathematically, the process is performed by minimizing the correlation function that is defined to match the similarity between the correlation window in the reference and deformed images.

Figures 3 and 4 show the $X$ and $Y$ velocity components, respectively, superimposed on the visual images of the cutting process for the two different cutting conditions. Strain rates are more sensitive to noises than the velocity fields because strain rates involve differentiation. This means any noise in the velocity field will magnify errors in the strain field.

To smooth the velocity gradients, a moving least-square (LS) plane fitting method is used to find a plane that is closest to the original subset

$$
\begin{gathered}
\min \sum_{i}\left[\left(u_{i}^{\mathrm{LSF}}-u_{i}\right)^{2}+\left(v_{i}^{\mathrm{LSF}}-v_{i}\right)^{2}\right] \\
u_{i}^{\mathrm{LSF}}=a_{i}^{\mathrm{LSF}}+u_{X}^{\mathrm{LSF}} X_{i}+u_{Y}^{\mathrm{LSF}} Y_{i} \\
v_{i}^{\mathrm{LSF}}=b_{i}^{\mathrm{LSF}}+v_{X}^{\mathrm{LSF}} X_{i}+v_{Y}^{\mathrm{LSF}} Y_{i}
\end{gathered}
$$

where $a_{i}^{\mathrm{LSF}}, b_{i}^{\mathrm{LSF}}, u_{X}^{\mathrm{LSF}}=(\partial u / \partial X)^{\mathrm{LSF}}, u_{Y}^{\mathrm{LSF}}=(\partial u / \partial Y)^{\mathrm{LSF}}, v_{X}^{\mathrm{LSF}}=$ $(\partial v / \partial X)^{\mathrm{LSF}}$, and $v_{Y}^{\mathrm{LSF}}=(\partial v / \partial Y)^{\mathrm{LSF}}$ describe the closest plane, and $\left(u_{i}, v_{i}\right)$ is the DIC determined velocity at point $\left(X_{i}, Y_{i}\right)$. Under plane strain condition, the equivalent strain rate is calculated as shown in the following equation:

$$
\dot{\bar{\varepsilon}}=\frac{1}{t_{\text {int }}} \overline{\frac{2}{3}\left[\left(u_{X}^{\mathrm{LSF}}\right)^{2}+\left(v_{Y}^{\mathrm{LSF}}\right)^{2}+0.5\left(u_{Y}^{\mathrm{LSF}}+v_{X}^{\mathrm{LSF}}\right)^{2}\right]}
$$

where $t_{\text {int }}$ is the interval time. The equivalent plastic strain rate fields of cutting zones for different cutting conditions are given in Fig. 5. It can be seen that the strain rate reaches $5 \mathrm{E} 4 \mathrm{~s}^{-1}$ for $V=150 \mathrm{~m} / \mathrm{min}$ and $h=0.15 \mathrm{~mm}$. While adopting $V=180 \mathrm{~m} / \mathrm{min}$ and $h=0.1 \mathrm{~mm}$, the strain rate approaches 1E5 s $\mathrm{s}^{-1}$. From Fig. 5(a), we can find the severe plastic strain rate distribution during the tertiary deformation zone (machined surface), while no such information is shown in Fig. 5(b). This is due to the fact that a small chip sliding over 


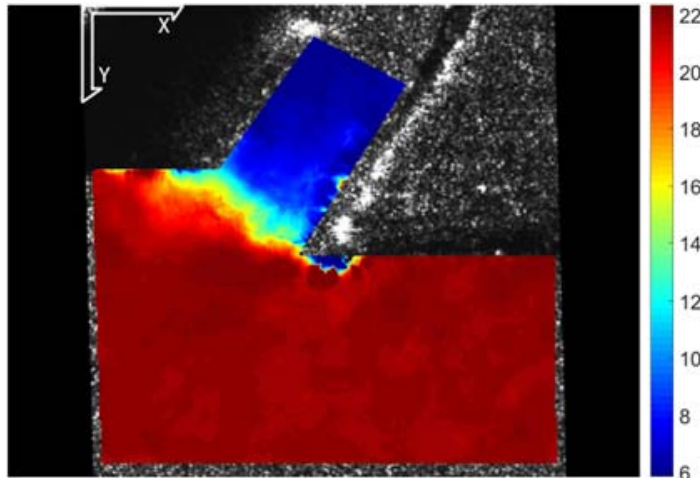

(a)

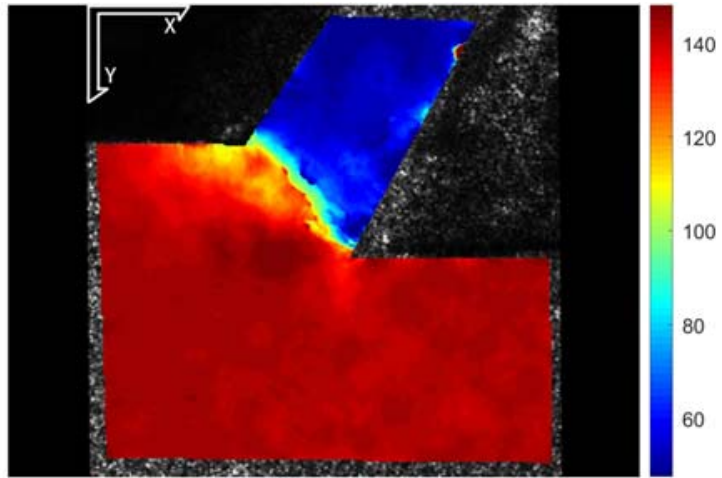

(b)

Fig. 3 Velocity component ( $\mathrm{m} / \mathrm{min}$ ) along $X$ direction for the cutting conditions: (a) $V=30 \mathrm{~m} / \mathrm{min}, h=0.1 \mathrm{~mm}$; and (b) $V=150 \mathrm{~m} / \mathrm{min}, h=0.15 \mathrm{~mm}$

the tertiary deformation zone (see Fig. 6), which occurs frequently in a practical cutting process. Thus, the imaging of the moving chip, rather than the specimen material, is recorded by the double-shutter camera, resulting in an unusual strain rate distribution. However, this fact will not affect the plastic strain rate during the primary shear zone.

Assuming a start point $\mathbf{x}^{i}$, the upstream point $\mathbf{x}^{i+1}$ could be derived based on the Taylor series expansion method:

$$
\mathbf{x}^{i+1} \approx \mathbf{x}^{i}+\mathbf{v}_{s} \Delta t
$$

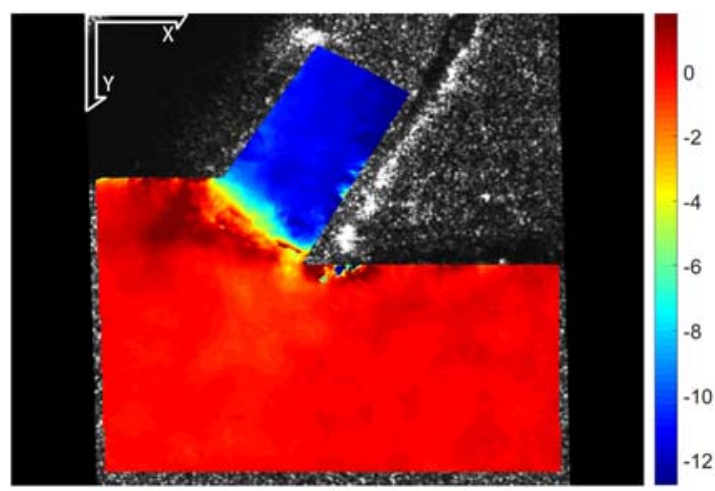

(a) where $\mathbf{v}_{s}=\partial \mathbf{x}^{i} / \partial t$ is the velocity at point $\mathbf{x}^{i}$. Then, the equivalent strain is obtained by accumulating the strain increments along the pathlines of the flow $l$, as follows:

$$
\varepsilon=\int_{l} \dot{\varepsilon}^{p} d t
$$

In a steady-state cutting process, the pathlines of the material normally coincide with the flow streamlines. The streamlines of the flow are shown in Fig. 7. As can be seen that the cutting process produces the laminar flow of materials in machined surface, also

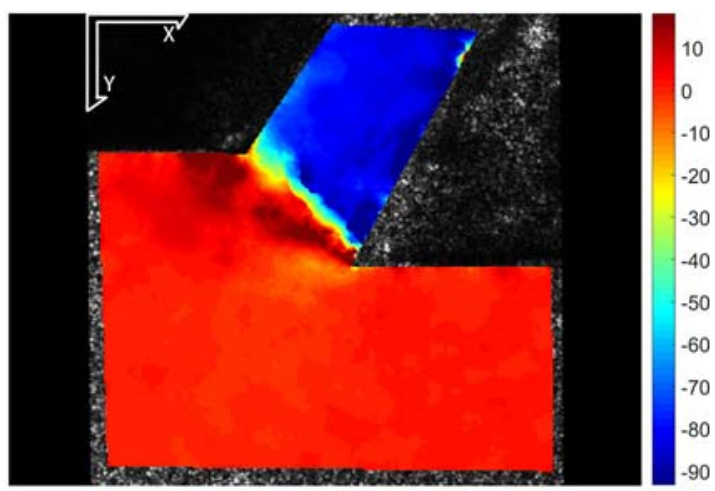

(b)

Fig. 4 Velocity component ( $\mathrm{m} / \mathrm{min}$ ) along $Y$ direction for the cutting conditions: (a) $V=30 \mathrm{~m} / \mathrm{min}, h=0.1 \mathrm{~mm}$; and (b) $V=150 \mathrm{~m} / \mathrm{min}, h=0.15 \mathrm{~mm}$

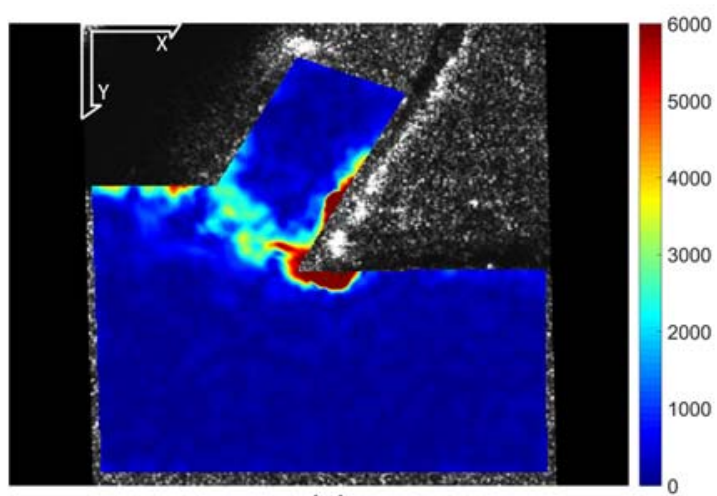

(a)

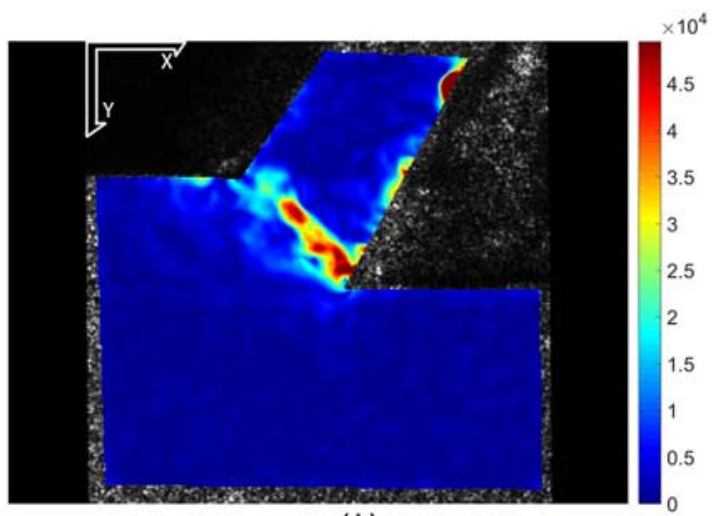

(b)

Fig. 5 Equivalent plastic strain rate $\left(\mathrm{s}^{-1}\right)$ for cutting conditions: (a) $V=30 \mathrm{~m} / \mathrm{min}, h=0.1 \mathrm{~mm}$; and (b) $V=150 \mathrm{~m} / \mathrm{min}$, $h=0.15 \mathrm{~mm}$ 


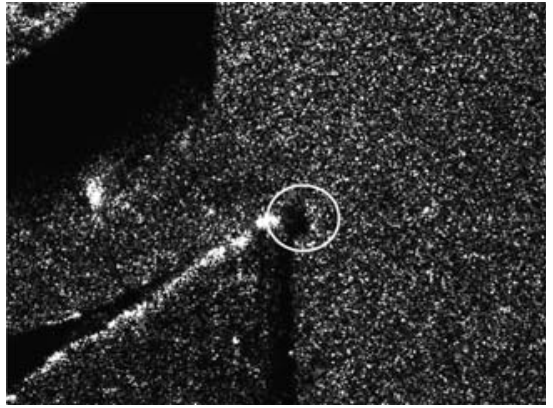

Fig. 6 Small chip (circle) sliding over the machined surface

reported in Ref. [21]. After the integration in Eq. (5) along the streamlines, the equivalent strain fields for the given two cutting conditions are presented in Fig. 8. Also we find the unusual high strain occurrence on the machined surface, see Fig. 8(a). The phenomenon is caused by the occurrence of small chip sliding, see Figs. 5(a) and 6. The equivalent plastic strain calculation during the primary shear zone is performed by integrations of strain rate in the same zone and will be completely unaffected by the tertiary deformation zone.

\section{Identification of the Constitutive Model Coefficients}

Figure 9 shows the flowchart of the procedure to identify the constitutive model coefficients. The implementation of this flowchart is detailed in the algorithm as follows:

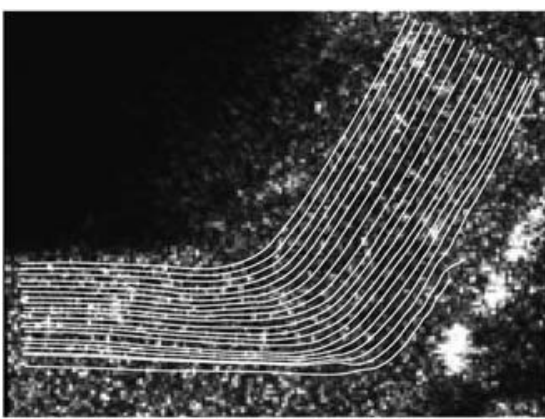

(a)
Algorithm Constitutive model coefficients identification

Input: Flow stress curves obtained from QS compression tests; cutting conditions $V, h, \gamma, \alpha$, and $w$; initial constitutive constants $C_{0}$ and $m_{0}$; threshold $\epsilon$ specifying the algorithm convergence.

Output: $A, B$, and $n$ constitutive model coefficients identified from QS compression tests; $C$ and $m$ constitutive model coefficients, obtained by applying the LS method.

Step 0:

(1) Set $k=0$ and $\delta_{0}=1 \mathrm{E} 10$;

(2) With $A, B, C_{k}, m_{k}$, and $n$, calculate temperatures $T_{k}(i)$, stresses $\sigma_{k}(i)$ and $\tau_{k}(i)$, and cutting forces $f_{k}^{S}(i)$, where $i=1,2, \ldots, N$;

(3) Compute $\delta_{k+1}=\sum_{i=1}^{N}\left[f_{k}^{S}(i)-F^{S}(i)\right]^{2}$;

(4) If $\frac{\left|\delta_{k+1}-\delta_{k}\right|}{\delta_{k+1}} \times 100 \%<\epsilon$ exit and report constitutive model coefficients $C=C_{k}, m=m_{k}$, in addition to $A, B$, and $n$; Else go to Step 1;

\section{Step 1:}

(1) Solve the least square optimization problem $\mathbf{L S}$ to determine the increments of $\Delta C_{k}$ and $\Delta m_{k}$;

(2) Update $C_{k}=C_{k}+\Delta C_{k}$ and $m_{k}=m_{k}+\Delta m_{k}$;

(3) Update $k=k+1$; go to Step 0: (2);

In Fig. $9, F^{S}(i)$ and $f_{k}^{S}(i),(i=1,2, \ldots, N)$ are the measured and calculated shear forces along the shear plane, respectively; $N$ is the number of the cutting tests based on the cutting conditions given in Table 2; temperature $T$, stresses $(\sigma$ and $\tau$ ), and cutting forces $F$ are calculated as explained in the next section

Fig. 7 Streamlines of the flow for cutting conditions: (a) $V=30 \mathrm{~m} / \mathrm{min}, h=0.1 \mathrm{~mm}$; and (b) $V=150 \mathrm{~m} / \mathrm{min}, h=0.15 \mathrm{~mm}$

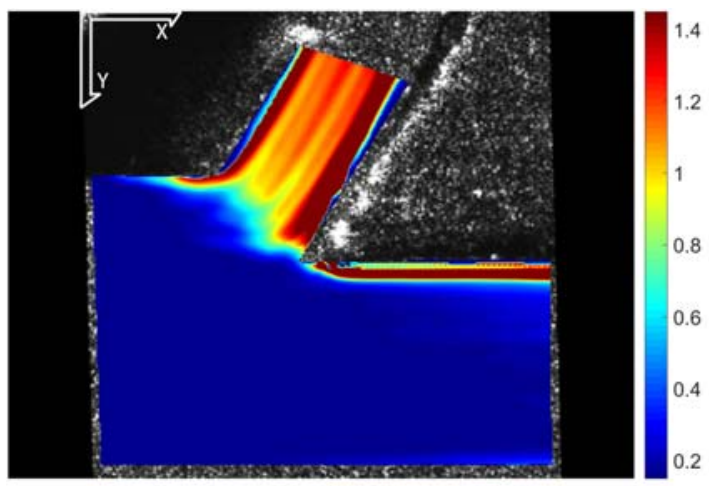

(a)

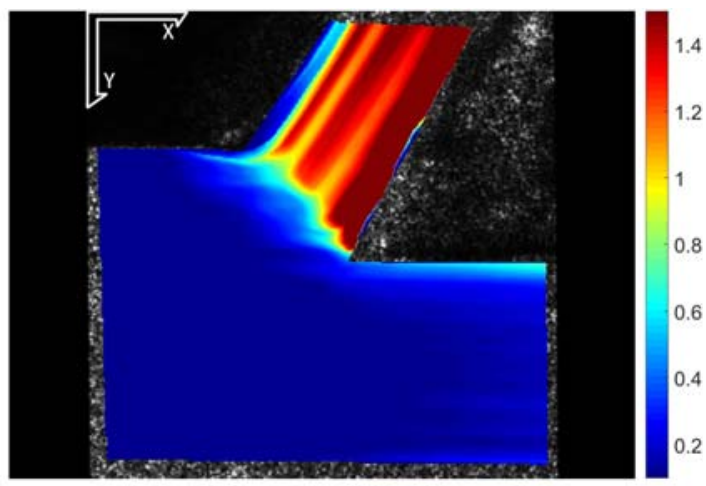

(b)

Fig. 8 Equivalent plastic strain for cutting conditions: (a) $V=30 \mathrm{~m} / \mathrm{min}, h=0.1 \mathrm{~mm}$; and (b) $V=150 \mathrm{~m} / \mathrm{min}$, $h=0.15 \mathrm{~mm}$ 


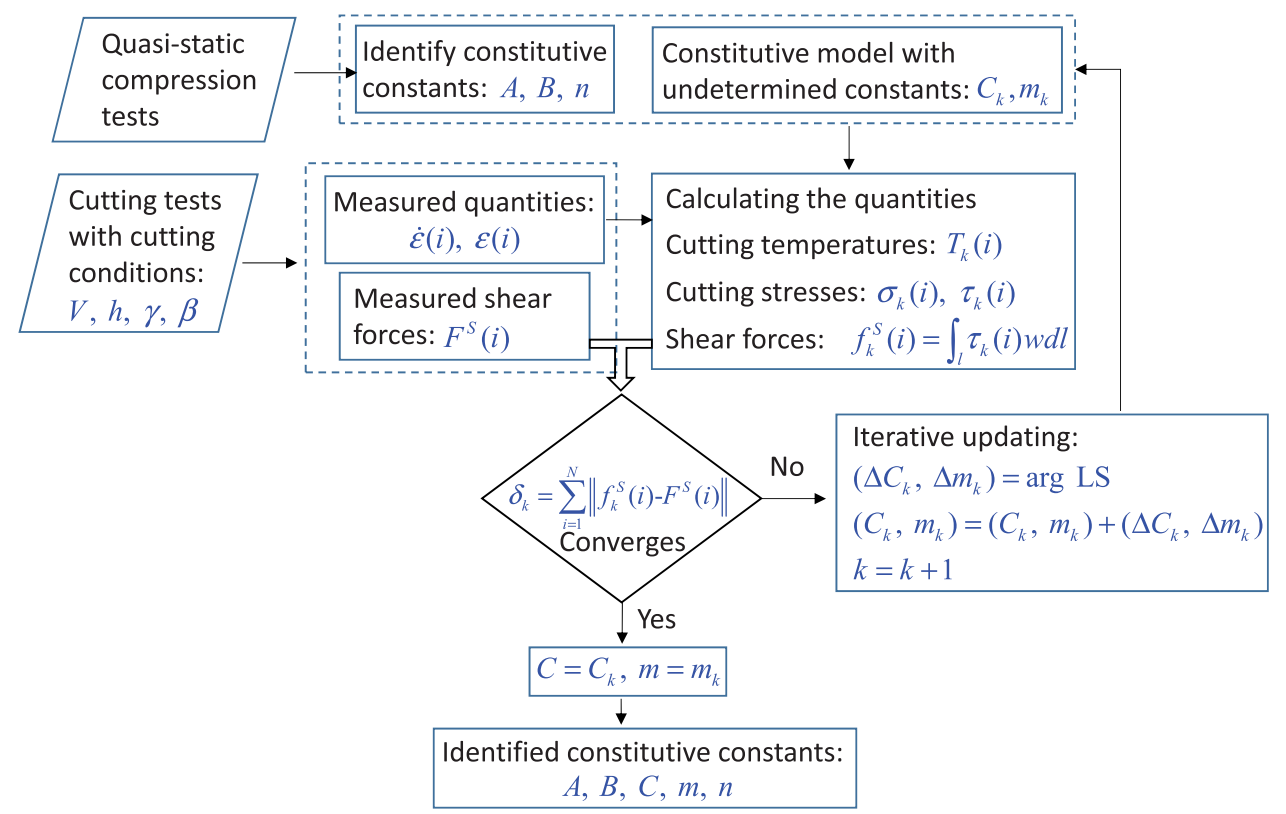

Fig. 9 Flowchart of the proposed approach for identifying the constitutive constants

5.1 Determination of Initial Constitutive Model Coefficients. QS compression tests have been conducted to determine the constitutive model coefficients $A, B$, and $n$ under the following conditions: stain rate of $0.001 \mathrm{~s}^{-1}$ and room temperature of $25^{\circ} \mathrm{C}$, using a Gleeble 3500-GTC machine. The cylindrical specimens for QS compression tests are $5 \mathrm{~mm}$ in diameter and $5 \mathrm{~mm}$ in height. The loading and displacement are recorded during the tests. Then, the true stress versus true strain curve is calculated, as shown in Fig. 10, which is also reported in Ref. [22]. As discussed in Sec. 2, using the J-C constitutive model, Eq. (1) is reduced to $\sigma=A+B \varepsilon^{n}$ under QS conditions. Therefore, constitutive model coefficients $A, B$, and $n$ can be obtained by nonlinear fitting of the true stress versus true strain curve shown in Fig. 10, after removing the elastic part. The obtained coefficients values are the following:

$$
A=295 \mathrm{MPa}, \quad B=795.5 \mathrm{MPa}, \quad n=0.4757
$$

Other coefficients $C$ and $m$ are predefined using empirical values as follows:

$$
C=0.05, \quad m=0.8
$$

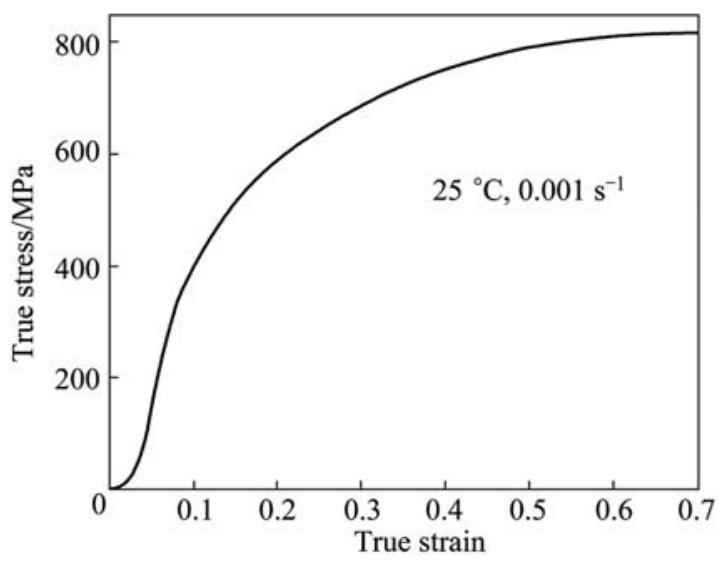

Fig. 10 True stress versus true strain curve of NAB in QS compression test
5.2 Calculation of Cutting Forces and Temperatures. In order to make these calculations possible, an assumption is introduced. The deformation taking place at the primary shear zone is considered to be occurring by shearing in a shear plane, represented in Fig. 11 by the projection line $A B$ in the $X Y$ plane. Therefore, a shear force $F^{S}$ along the shear plane (resulting from the decomposition of the resultant force according to the force diagram shown in Fig. $11(a)$ ) and the predicted shear force $f^{S}$ are compared, as shown in Fig. 9. This shear force $F^{S}$ is represented by the following equation:

$$
F^{S}=R \cos (\varphi+\beta)
$$

where $R=\sqrt{F_{C}^{2}+F_{T}^{2}}$ is the resultant force with direction of $\beta=\tan ^{-1}$ $\left(F_{T} / F_{C}\right) . \quad F_{C}$ and $F_{T}$ are the measured tangential and thrust forces, respectively; and $\varphi$ is the shear angle. It should be noted that the tool-chip friction coefficient plays no role during the calculation of the shear force, because the shear force can be determined from the decomposition of the measured resultant force along the shear plane, which is identified from the experiment (see Fig. 11(b)).

With the measured equivalent strain $\varepsilon$, strain rate $\dot{\varepsilon}$, and predicted temperature $T_{A B}$, the flow stress $\sigma$ in the shear zone could be derived based on the constitutive model given in Eq. (1). According to the classic orthogonal cutting models, such as the Oxley's model, the stress state in the shear zone is assumed as pure shear along the shear plane $A B$. Besides all the material lying inside, the shear zone yields as great distortion occurs. Based on the above assumptions, the shear stress $\tau$ along the shear plane $A B$ could be derived as follows:

$$
\tau=\sigma(C, m) / \sqrt{3}
$$

where $\sigma(C, m)$ is the yield strength along $A B$ as a function of strain rate sensitivity $C$ and thermal softening coefficient $m$, since the other constitutive model coefficients are identified from QS tests, as shown in Fig. 9. Furthermore, the shear force in the primary shear zone could be predicted by integrating the shear stress $\tau$ along the shear plane $A B$ :

$$
f^{S}=\int_{A}^{B} \tau w d l_{A B}
$$

Here, the shear plane $A B$ determination acts as an important step to calculate shear force $f^{S}$, as well as shear angle $\varphi$. A square zone inside the primary shear zone c-d-f-e (see Fig. 11(b)), where the 


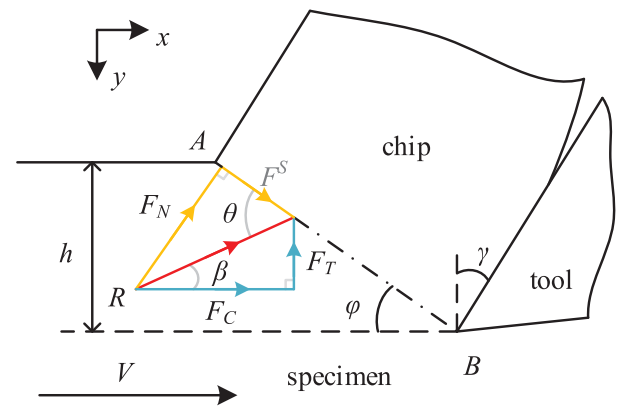

(a)

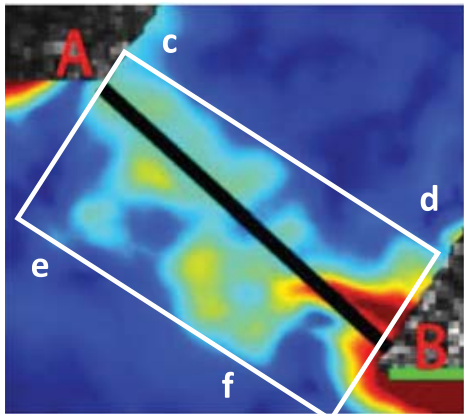

(b)

Fig. 11 Shear plane analysis: (a) force diagram and (b) determination of shear plane $A B$

equivalent strain rates are greater than a preset one $|\dot{\bar{\varepsilon}}|$, is selected. Then, the strain rates are sampled randomly in the square zone; thus, the shear plane $A B$ can be determined using the least-square method. It can be seen that the selection of the shear band "c-d-f-e" is not unique. After several trials of different squares "c-d-f-e," we conclude that the different shear planes $A B$ coincident well.

Although fabricate instrumented cutting tools with embedded thermocouples were developed to accurately measure the toolchip interface temperature [23], the direct measurement of temperature inside the primary zone is still a challenge. Taking this challenge into account, the temperature is computed by equating overall temperature rise of the material in moving through the primary shear zone and the total plastic work in the primary shear zone [24]. Then, this temperature is compared with that one obtained by finite element simulation of the orthogonal cutting process. The temperature in the primary shear plane $T$ can be calculated from the following equation:

$$
\int_{T_{W}}^{T} \frac{\rho C_{p}}{1-\left(\frac{T-T_{r}}{T_{m}-T_{r}}\right)^{m}} d T=(1-\eta)\left(A \varepsilon+\frac{B}{n+1} \varepsilon^{n+1}\right)\left(1+C \ln \frac{\dot{\varepsilon}}{\dot{\varepsilon}_{0}}\right)
$$

where $T_{W}$ is the initial specimen temperature, $\rho$ is the density of the specimen material $\left(\rho=7530 \mathrm{~kg} / \mathrm{m}^{3}\right), C_{p}$ is the specific heat of the specimen material $\left(C_{p}=418 \mathrm{~J} / \mathrm{kg} \mathrm{K}\right), \varepsilon$ is the average strain, $\dot{\varepsilon}$ is

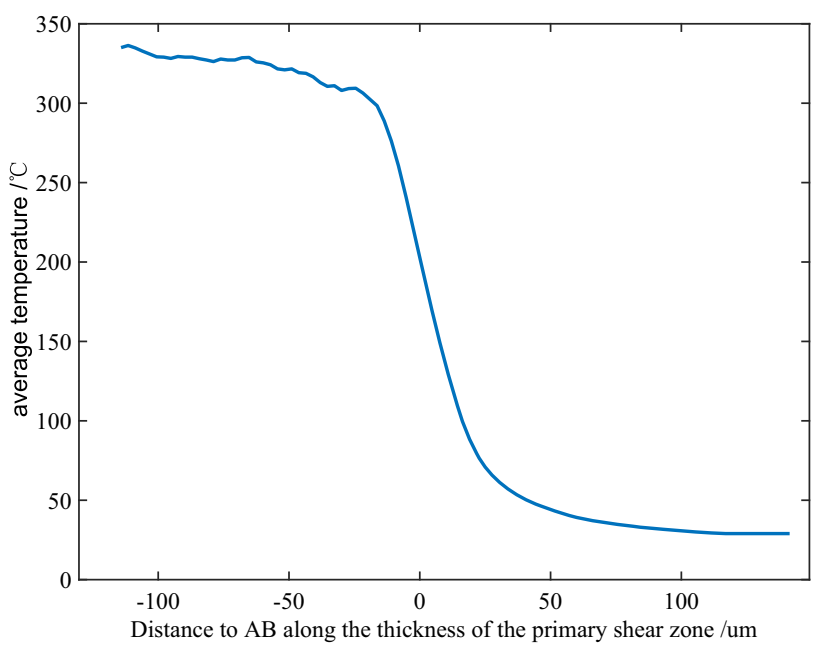

(a) the average strain rate, and $\eta$ is the heat partition coefficient (a portion of heat conducted to the specimen from the shear zone), which can be given as follows:

$$
\begin{array}{lll}
\eta=0.5-0.35 \lg \left(R_{T} \tan \varphi\right) & \text { for } \quad 0.04 \leq R_{T} \tan \varphi \leq 10 \\
\eta=0.3-0.15 \lg \left(R_{T} \tan \varphi\right) & \text { for } \quad R_{T} \tan \varphi>10
\end{array}
$$

where $R_{T}$ is the nondimensional thermal number given by:

$$
R_{T}=\rho C_{p} V h / \lambda
$$

where $\lambda$ is the thermal conductivity of the specimen material $(\lambda=$ $42 \mathrm{~W} /(\mathrm{m} \mathrm{K})) . \eta$ is calculated using Eqs. (12) and (13), which will depend on shear angle and cutting parameters. For specified case 1: $V=30 \mathrm{~m} / \mathrm{min}, h=0.1 \mathrm{~mm}$, and $\eta_{1}=0.3054$, while for case 2: $V=150 \mathrm{~m} / \mathrm{min}, h=0.15 \mathrm{~mm}$, and $\eta_{2}=0.0804$. Figure 12 shows the temperature distribution of the two cases under the initial constitutive parameters, and the value at the shear band $A B$ is $202^{\circ} \mathrm{C}$ and $290{ }^{\circ} \mathrm{C}$, respectively.

5.3 Identification of $C$ and $m$ Constitutive Model Coefficients. Using the cutting conditions shown in Table 2, 12 orthogonal cutting tests were performed corresponding to 12 combinations of $h$ and $V$. Each test was repeated five times, so 60 cutting tests in total are performed. Images of the cutting zone and the forces are recorded during each test.

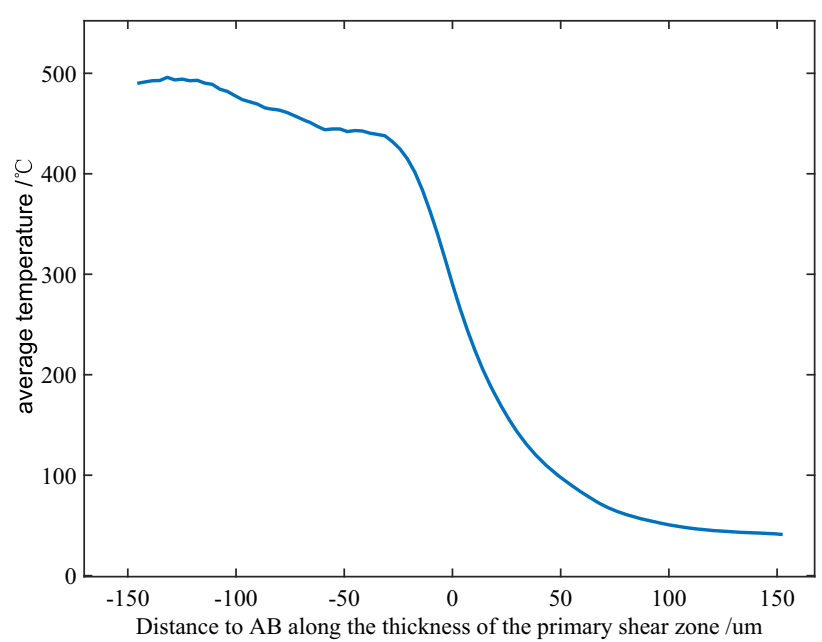

(b)

Fig. 12 Temperature distribution in the primary shear zones for cutting conditions: (a) $V=30 \mathrm{~m} / \mathrm{min}, h=0.1 \mathrm{~mm}$; and (b) $V=150 \mathrm{~m} / \mathrm{min}, h=0.15 \mathrm{~mm}$ 


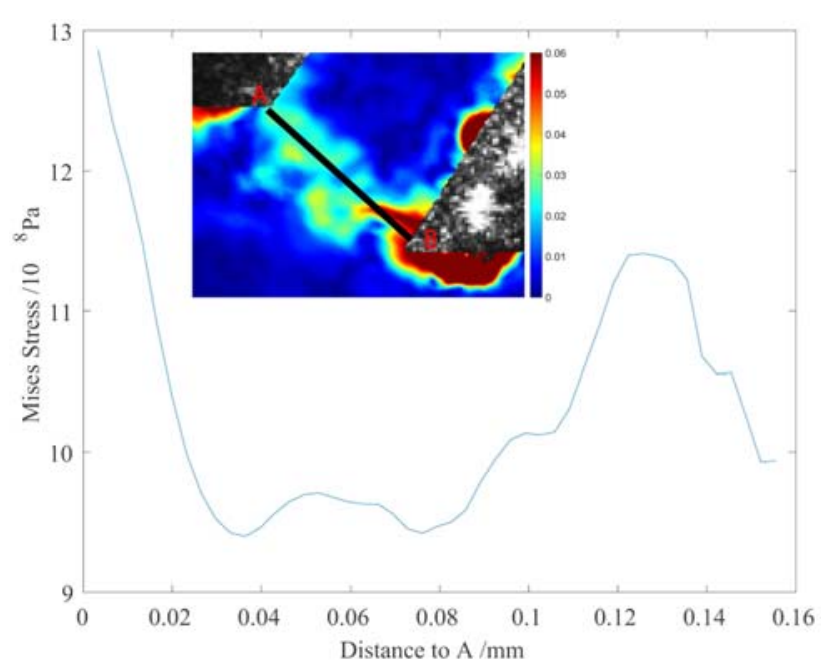

(a)

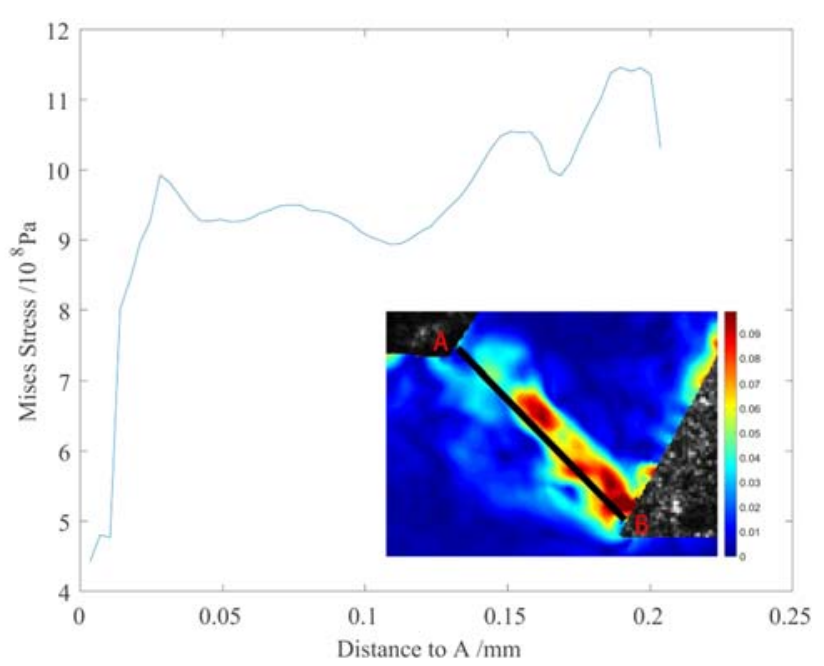

(b)

Fig. 13 Stresses along shear planes for cutting conditions: (a) $V=30 \mathrm{~m} / \mathrm{min}, h=0.1 \mathrm{~mm}$; and (b) $V=150 \mathrm{~m} / \mathrm{min}, h=0.15 \mathrm{~mm}$

Table 3 Calculated shear forces for case $1: V=30 \mathrm{~m} / \mathrm{min}, h=0.1 \mathrm{~mm}$ and case $2: V=150 \mathrm{~m} / \mathrm{min}, h=0.15 \mathrm{~mm}$, comparing against the measured ones (unit: $\mathrm{N}$ )

\begin{tabular}{lcccrrr}
\hline \hline Iteration number $k$ & 0 & 1 & 3 & 5 & 7 & Measured \\
\hline Case 1 & 324.0651 & 312.6055 & 289.3602 & 258.9508 & 256.9318 \\
Case 2 & 342.5680 & 332.6385 & 310.9758 & 276.9696 & 274.2227 & 257.0215 \\
\hline \hline
\end{tabular}

As shown in Fig. 9, $C$ and $m$ constitutive model coefficients are calculated from the sequential LS optimization method given by,

$$
\text { LS } \min _{\left(C_{k}, m_{k}\right)} \delta_{k+1}=\sum_{i=1}^{N}\left[f_{k}^{S}(i)-F^{S}(i)\right]^{2}
$$

where $k$ is the iteration number. Notice that $f_{k}^{S}$ is a function of $C$ and $m$, i.e., $f_{k}^{S}=f_{k}^{S}[C, m]$. More important, it is differentiable with respect to $C$ and $m$. Thus, the $\mathbf{L S}$ problem can be solved by the Gauss-Newton method, and the optimization results $\left(\Delta C_{k}, \Delta m_{k}\right)=\arg \mathbf{L S}$ are obtained. The initial values $C$ and $m$ are predefined as $C_{0}=0.05$ and $m_{0}=0.8$, as given in Sec. 5.1. Then, new candidate $C_{k}$ and $m_{k}$ is generated, as stated in Step 1: (2) of the Algorithm. As a result, a new $\delta_{k+1}$ is obtained, and the convergence criteria $\frac{\left|\delta_{k+1}-\delta_{k}\right|}{\delta_{k+1}}<\epsilon$ are evaluated. The iterations continue until the convergence criteria is satisfied. Finally, the constitutive constants $C=C_{k}$ and $m=m_{k}$ are reached. Setting up the optimization convergence threshold $\epsilon=0.1 \%$, after nine times iterations, the sequential optimization terminates at $\epsilon=0.093 \%$. Finally, the constitutive model coefficients $C=C_{k}$ and $m=m_{k}$ are obtained. Figure 13 shows the resulted stresses $\sigma$ along the shear planes for the two cases, case 1: $V=30 \mathrm{~m} / \mathrm{min}, h=0.1 \mathrm{~mm}$ and case 2: $V=150 \mathrm{~m} / \mathrm{min}, h=0.15 \mathrm{~mm}$. The calculated shear forces $f_{k}^{S}(i)$ and temperature $T_{k}(i)$ in intermediate iteration steps and the measured ones for both cases are listed in Tables 3 and 4. Signals of the measured cutting and thrust forces and shear forces along shear plane are given in Fig. 14 for both cases. Remember the measured shear forces (bold ones) in Table 3 are the projection components of measured cutting and thrust forces onto the shear plane, so $F^{S}=F_{C} \cos \varphi+F_{T} \sin \varphi$. The corresponding shear angles for cases 1 and 2 are $43.84 \mathrm{deg}$ and $45.99 \mathrm{deg}$, respectively. The equivalent strains on the shear plane are 0.70 and 0.77 for cases 1 and 2, respectively. Furthermore, the equivalent plastic strain exceeds 1.15 while using $V=180 \mathrm{~m} / \mathrm{min}$ and $h=0.15 \mathrm{~mm}$.

The iterative values of $C$ and $m$ are listed in Table 5. Finally, the constitutive model coefficients for NAB are obtained, as given in Table 6 .
5.4 Comparison With Finite Element Simulations. By using the J-C material model with the identified coefficients, finite element simulations of the orthogonal cutting process are performed. The output of the simulations includes the strain, strain rate, and temperature fields as well as the forces. Commercial finite element software DEFORM is used to conduct such simulations. Adaptive remeshing of the workpiece is enabled during the simulation process, and the mesh of the workpiece consists of about 4000 elements with the minimum element size around $2 \mu \mathrm{m}$ near the cutting tool tip. The cutting conditions for finite element simulations are the specified two cutting parameter sets used in experiments, i.e., case 1: $V=30 \mathrm{~m} / \mathrm{min}, h=0.1 \mathrm{~mm}$; and case $2: V=150 \mathrm{~m} / \mathrm{min}, h=$ $0.15 \mathrm{~mm}$, as well as the cutting tool geometry, as given in Table 2 . Average shear friction factors of 0.6 and 0.3 , which were determined using a universal friction and wear testing machine, are used for cases 1 and 2, respectively. Contour plots of strain rate from finite element analysis are given in Fig. 15. It can be seen that the strain rate field, including the intensity as well as

Table 4 Calculated temperatures for case 1: $V=30 \mathrm{~m} / \mathrm{min}$, $h=0.1 \mathrm{~mm}$ and case $2: V=150 \mathrm{~m} / \mathrm{min}, h=0.15 \mathrm{~mm}$ (unit: ${ }^{\circ} \mathrm{C}$ )

\begin{tabular}{lcccccc}
\hline \hline Iteration number $k$ & 0 & 1 & 3 & 5 & 7 & 9 \\
\hline Case 1 & 201 & 193 & 177 & 161 & 161 & 162 \\
Case 2 & 290 & 278 & 254 & 228 & 228 & 228 \\
\hline \hline
\end{tabular}

Table 5 Optimization results of constitutive constants $C$ and $m$

\begin{tabular}{lcccccc}
\hline \hline $\begin{array}{l}\text { Iteration } \\
\text { number } k\end{array}$ & 0 & 1 & 3 & 5 & 7 & 9 \\
\hline$C_{k}$ & 0.0500 & 0.0417 & 0.0285 & 0.0190 & 0.0198 & 0.0217 \\
$m_{k}$ & 0.8000 & 0.8493 & 0.9247 & 0.8560 & 0.8177 & 0.7775 \\
\hline \hline
\end{tabular}




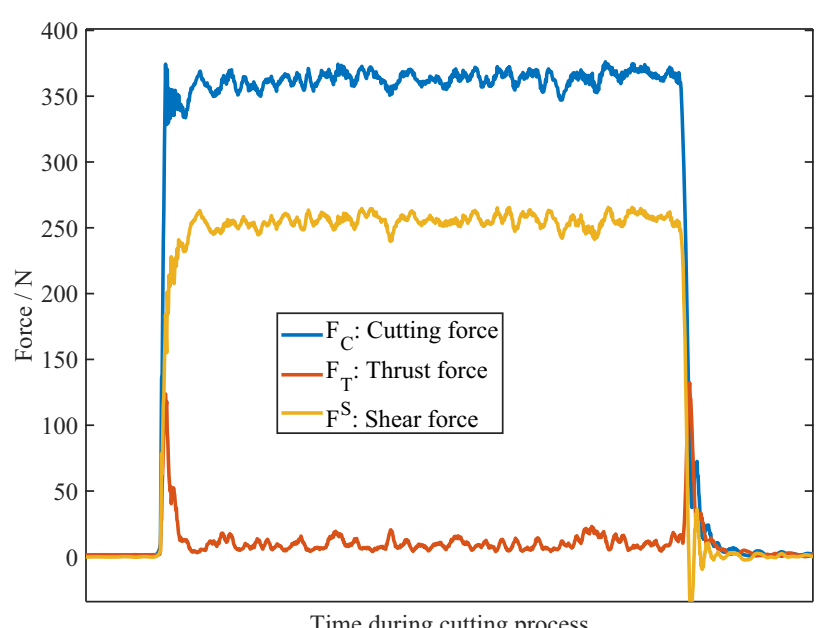

Time during cutting process

(a)

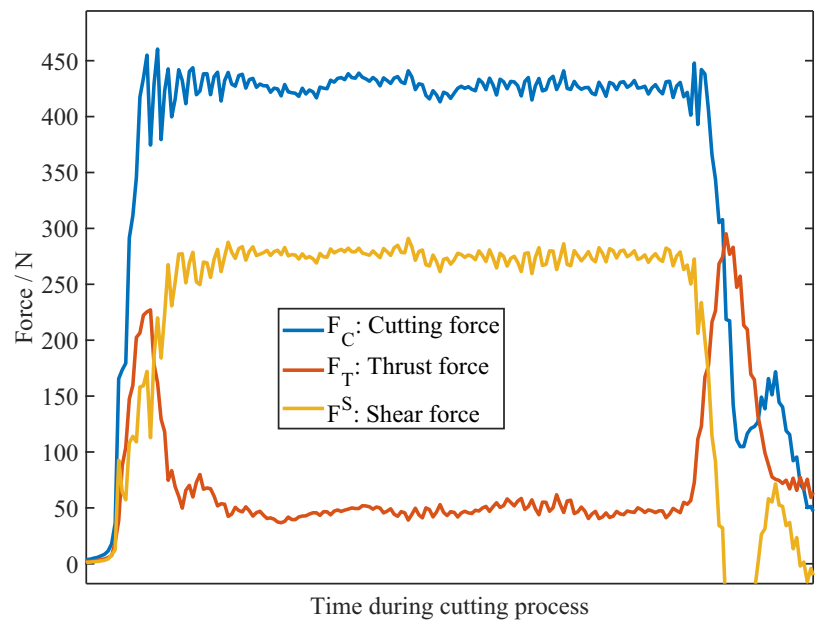

(b)

Fig. 14 Shear forces $F^{S}$ derived from $F_{C}$ and $F_{T}$ for cutting conditions: (a) $V=30 \mathrm{~m} / \mathrm{min}, h=0.1 \mathrm{~mm}$; and $(b) V=150 \mathrm{~m} / \mathrm{min}$, $h=0.15 \mathrm{~mm}$

Table 6 Identified material constitutive constants of NAB in J-C model

\begin{tabular}{lcccc}
\hline \hline$A$ & $B$ & $C$ & $m$ & $n$ \\
\hline $295 \mathrm{MPa}$ & $795.5 \mathrm{MPa}$ & 0.0217 & 0.7775 & 0.4757 \\
\hline \hline
\end{tabular}

distributions are considerably consistent with the imaging-based one, and see Fig. 5.

Contour plots of equivalent plastic strain from finite element analysis are given in Fig. 16. We can see that the finite element simulated strains are a bit lower than the measured values due to the DIC errors, and finite element simulation deviations considering the identified constitutive model coefficients are only valid for specific ranges of strain, strain rate, and temperature although the strain distributions fit favorably with the measured ones (Fig. 8).

Contour plots of temperatures from finite element analysis are given in Fig. 17. It can be seen that the temperatures along the shear plane are around $160^{\circ} \mathrm{C}$ and $210^{\circ} \mathrm{C}$, respectively. These temperatures are very consistent with the ones calculated by the above-presented algorithm for identifying the constitutive model coefficients (see Table 4). The simulated forces are $F_{C}=357.5 \mathrm{~N}$ and $F_{T}=32.5 \mathrm{~N}$ for case 1 and $F_{C}=425 \mathrm{~N}$ and $F_{T}=65.8 \mathrm{~N}$ for case 2 . These forces are similar to the measured ones using the

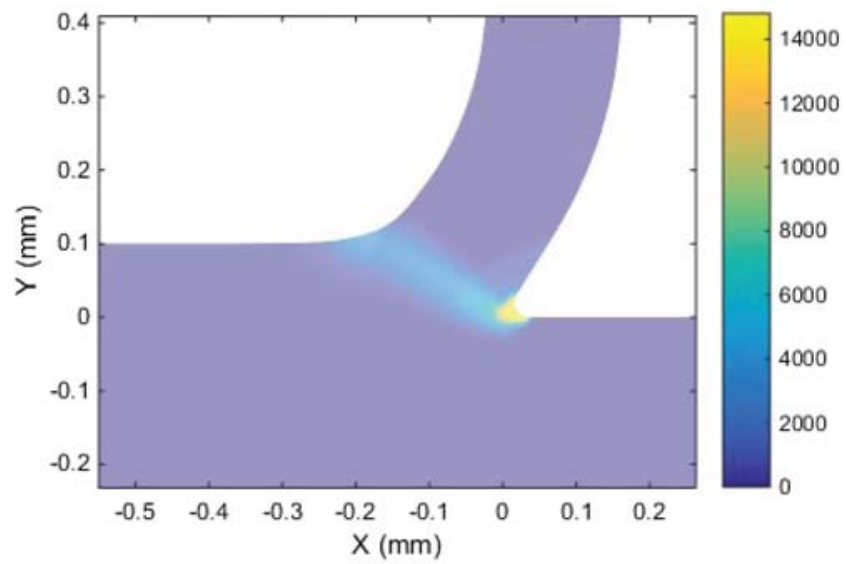

(a) dynamometer, presented in Fig. 14. These results show the success of the proposed imaging-based approach for identifying the material constitutive model coefficients.

\section{Conclusions and Remarks}

In this investigation, an in situ imaging-based methodology is developed for the identification of the material constitutive model coefficients, especially those associated with strain and strain rate effects. Based on the experimental work, DIC analysis, implementation of the algorithm for coefficients identification, and finite element simulations, the following conclusions and remarks can be drawn:

(1) A dedicated experimental setup, including functional module of cutting, lighting, and imaging, is developed to obtain the material velocity field in the cutting process. The strain and strain rate in shear zone are then acquired using DIC technique. The material constitutive model coefficients identification is realized by matching the calculated shear forces to measured ones on shear plane, which is modeled as an optimization problem and solved by a sequential least-square approach. The identified coefficients are input to commercial finite element software for simulation, while the output of the simulations are compared against the experimental results, and successful consistency is made.

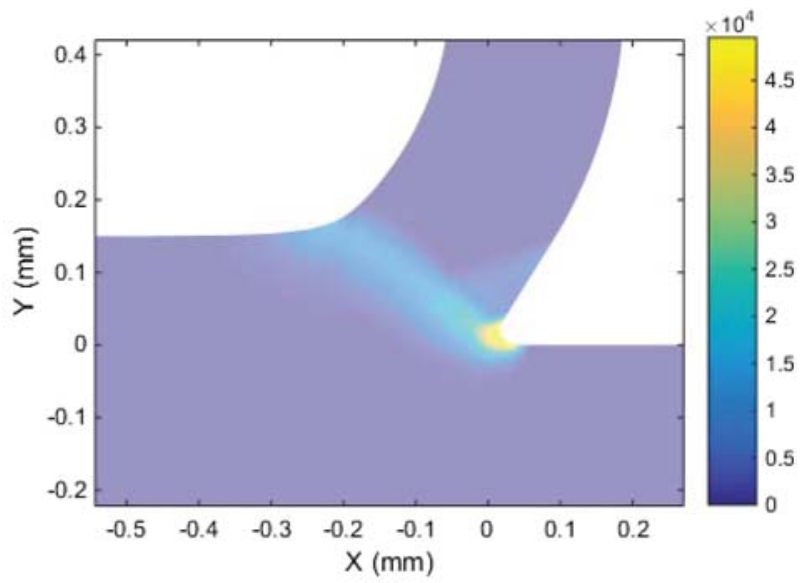

(b)

Fig. 15 Strain rate fields $\left(\mathrm{s}^{-1}\right)$ from finite element simulations: (a) $V=30 \mathrm{~m} / \mathrm{min}, h=0.1 \mathrm{~mm}$; and (b) $V=150 \mathrm{~m} / \mathrm{min}, h=0.15 \mathrm{~mm}$ 


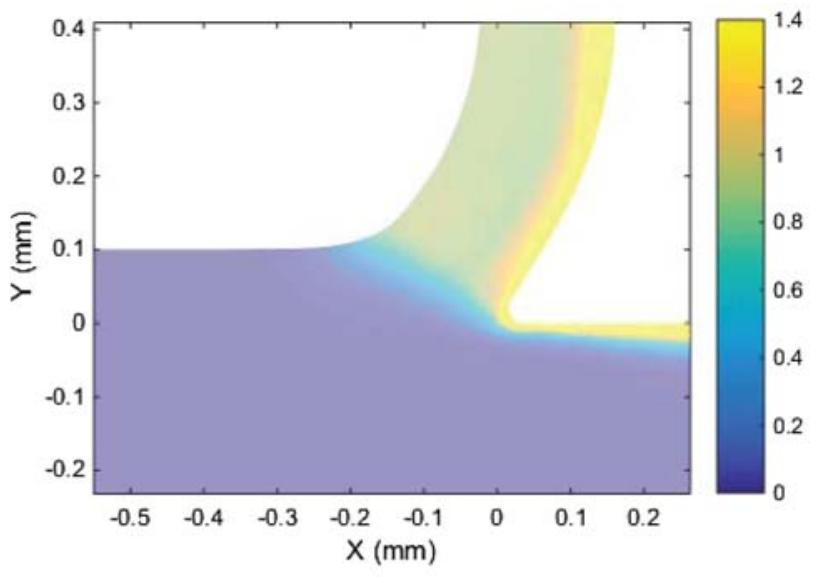

(a)

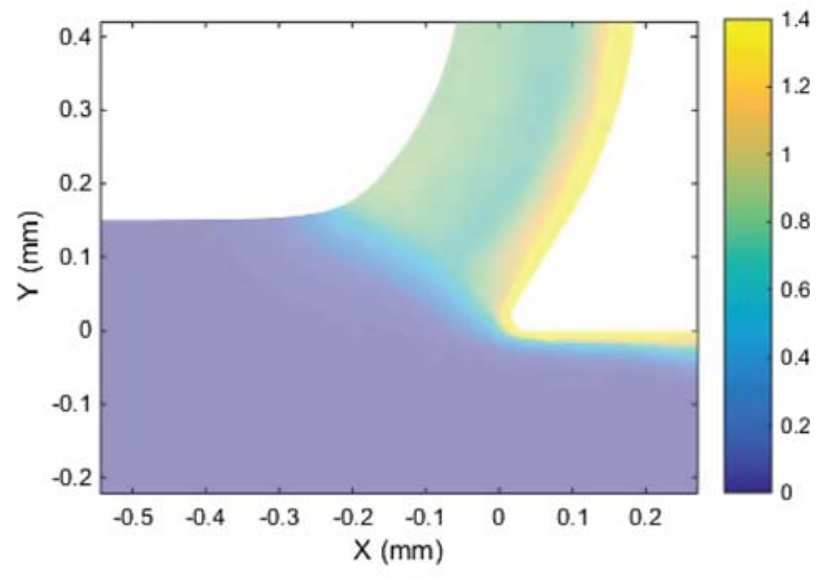

(b)

Fig. 16 Strain fields from finite element simulations: (a) $V=30 \mathrm{~m} / \mathrm{min}, h=0.1 \mathrm{~mm}$; and (b) $V=150 \mathrm{~m} / \mathrm{min}, h=0.15 \mathrm{~mm}$

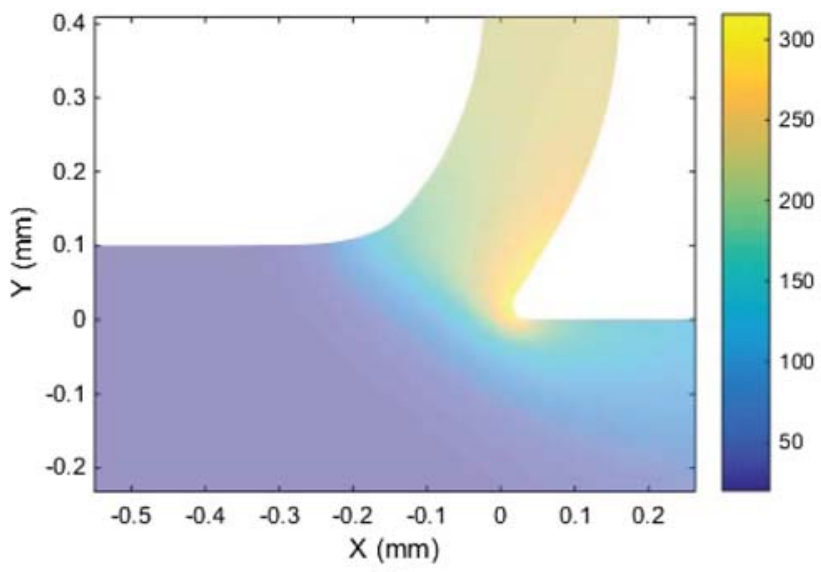

(a)

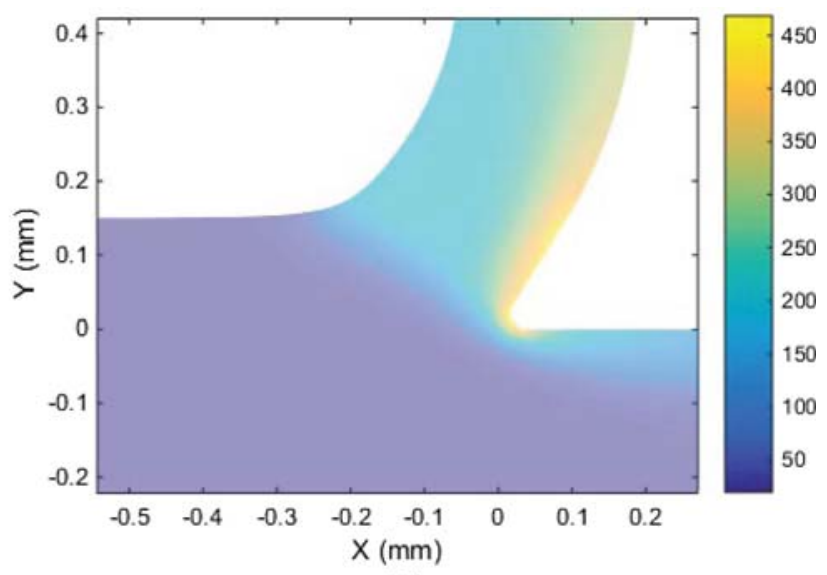

(b)

Fig. 17 Temperature fields $\left({ }^{\circ} \mathrm{C}\right)$ from finite element simulations: (a) $V=30 \mathrm{~m} / \mathrm{min}, h=0.1 \mathrm{~mm}$; and $(b) V=150 \mathrm{~m} / \mathrm{min}, h=0.15 \mathrm{~mm}$

(2) The constitutive model coefficients $C$ and $m$ are only valid for the cases where the work material is subjected to strain rates between $1 \mathrm{E} 3 \mathrm{~s}^{-1}$ and $1 \mathrm{E} 5 \mathrm{~s}^{-1}$. With more data including a wider range of strains and strain rates and forces obtained from the experiments, the same methodology can be used to obtain constitutive coefficients with more broad applications. So, this work is a very valuable contribution for the identification of constitutive model coefficients in severe plastic deformation processes, like high-speed machining. It also advances the understanding of material behavior under high strain and strain rate conditions in that a direct observation of the laminar flow of materials in cutting process is made.

(3) Some remarks. (i) To obtain high-resolution images for DIC analysis, an excellent lighting system during cutting is extremely important. In this experimental work, a solid-state laser to illuminate the cutting scene is used. However, the images are not clear enough to capture the plastic deformations accurately, while the cutting speed exceeds $300 \mathrm{~m} / \mathrm{min}$. The phenomenon of laser speckle disturbs the observation to workpiece itself, thus causing degradation the quality of images. So, further investigations on this topic are required and maybe a dedicated LED lighting system with enhanced luminous intensity is a better option. If so, the constitutive model coefficients can be identified for ultra-high speed cutting process. (ii) To overcome the free surface effect on the measurement accuracy, a three-dimension imaging system is a better choice to observe the metal flow from two directions, i.e., one is normal to the side surface, as done by the proposed paper, and the second is along the federate direction. (iii) To guarantee the reliability of the proposed imaging methodology, we are now planning to conduct SHPB experiments using conditions of higher levels of strain, strain rate, and temperatures. The outcome of the SHPB would provide a good comparison for verifying our proposed approach. (iv) The finite element simulations in this paper still have its limitations because the input material constitutive model coefficients identified from the primary shear zone cannot cover higher level of temperature in the secondary shear zone.

\section{Acknowledgment}

This work is partially supported by the National Natural Science Foundation of China (Grant Nos. 51722505 and 51721092; Funder ID: 10.13039/501100001809) and AECC project (Grant No. GJX20170176; Funder ID: 10.13039/ 100007320). The first author thanks Dr. Zhong-Tao Fu for the help on quasi-static compression tests.

\section{References}

[1] Zhao, H., and Gary, G., 1997, "A New Method for the Separation of Waves. Application to the SHPB Technique for an Unlimited Duration of Measurement," J. Mech. Phys. Solids, 45(7), pp. 1185-1202. 
[2] Lee, O. S., You, S. S., Chong, J. H., and Kang, H. S., 1998, "Dynamic Deformation Under a Modified Split Hopkinson Pressure Bar Experiment," KSME Int. J., 12(6), pp. 1143-1149.

[3] Field, J. E., Walley, S. M., Proud, W. G., Goldrein, H. T., and Siviour, C. R., 2004, "Review of Experimental Techniques for High Rate Deformation and Shock Studies," Int. J. Impact Eng., 30(7), pp. 725-775

[4] Shatla, M., Kerk, C., and Altan, T., 2001, "Process Modeling in Machining. Part I: Determination of Flow Stress Data," Int. J. Mach. Tools. Manuf., 41(10), pp. 1511-1534.

[5] Sartkulvanich, P., Koppka, F., and Altan, T., 2004, "Determination of Flow Stress for Metal Cutting Simulationa Progress Report," J. Mater. Process. Technol., 146(1), pp. 61-71.

[6] Özel, T., 1998, "Investigation of High Speed Flat End Milling Process," Ph.D. thesis, The Ohio State University, Columbus, $\mathrm{OH}$.

[7] Tounsi, N., Vincenti, J., Otho, A., and Elbestawi, M. A., 2002, "From the Basic Mechanics of Orthogonal Metal Cutting Toward the Identification of the Constitutive Equation,” Int. J. Mach. Tools. Manuf., 42(12), pp. 1373-1383.

[8] Shi, B., Attia, H., and Tounsi, N., 2010, "Identification of Material Constitutive Laws for Machining-Part I: An Analytical Model Describing the Stress, Strain, Strain Rate, and Temperature Fields in the Primary Shear Zone in Orthogonal Metal Cutting," ASME J. Manuf. Sci. Eng., 132(5), p. 051008.

[9] Shi, B., Attia, H., and Tounsi, N., 2010, "Identification of Material Constitutive Laws for Machining-Part II: Generation of the Constitutive Data and Validation of the Constitutive Law," ASME J. Manuf. Sci. Eng., 132(5), p. 051009.

[10] Oxley, P. L. B., 1989, The Mechanics of Machining: An Analytical Approach to Assessing Machinability, Ellis Horwood Limited, Chichester.

[11] Outeiro, J. C., Campocasso, S., Denguir, L. A., Fromentin, G., Vignal, V., and Poulachon, G., 2015, "Experimental and Numerical Assessment of Subsurface Plastic Deformation Induced by OFHC Copper Machining," CIRP Ann. Manuf. Technol., 64(1), pp. 53-56.

[12] Zhang, D., Zhang, X.-M., and Ding, H., 2016, "A Study on the Orthogona Cutting Mechanism Based on Experimental Determined Displacement and Temperature Fields," Procedia CIRP, 46, pp. 35-38.

[13] Zhang, D., Zhang, X.-M., Xu, W.-J., and Ding, H., 2017, "Stress Field Analysis in Orthogonal Cutting Process Using Digital Image Correlation Technique," ASME J. Manuf. Sci. Eng., 139(3), p. 031001.
[14] Zhang, D., Zhang, X.-M., Leopold, J., and Ding, H., 2017, "Subsurface Deformation Generated by Orthogonal Cutting: Analytical Modeling and Experimental Verification," ASME J. Manuf. Sci. Eng., 139(9), p. 094502.

[15] Xu, W.-J., Zhang, X.-M., Leopold, J., and Ding, H., 2017, "Mechanism of Serrated Chip Formation in Cutting Process Using Digital Image Correlation Technique," Procedia CIRP, 58, pp. 146-151.

[16] Zhang, D., Zhang, X.-M., and Ding, H., 2018, "Hybrid DIC-FEM Approach for Modeling of Orthogonal Cutting Process," ASME J. Manuf. Sci. Eng., 140(4), p. 041018 .

[17] Lee, S., Hwang, J., Ravi Shankar, M., Chandrasekar, S., and Dale Compton, W., 2006, "Large Strain Deformation Field in Machining," Metallurg. Mater. Trans. A, 37(5), pp. 1633-1643.

[18] Baizeau, T., Campocasso, S., Fromentin, G., Rossi, F., and Poulachon, G., 2015, "Effect of Rake Angle on Strain Field During Orthogonal Cutting of Hardened Steel With C-BN Tools," Procedia CIRP, 31, pp. 166-171.

[19] Arriola, I., Whitenton, E., Heigel, J., and Arrazola, P. J., 2011, "Relationship Between Machinability Index and In-Process Parameters During Orthogonal Cutting of Steels," CIRP Ann. Manuf. Technol., 60(1), pp. 93-96.

[20] Harzallah, M., Pottier, T., Gilblas, R., Landon, Y., Mousseigne, M., and Senatore, J., 2018, "A Coupled In Situ Measurement of Temperature and Kinematic Fields in Ti-6Al-4V Serrated Chip Formation At Micro-Scale," Int. J. Mach. Tools. Manuf., 130-131, pp. 20-35.

[21] Sundaram, N. K., Guo, Y., and Chandrasekar, S., 2012, "Mesoscale Folding, Instability, and Disruption of Laminar Flow in Metal Surfaces," Phys. Rev. Lett., 109(10), p. 106001.

[22] Fu, Z.-T., 2015, "Research on Feedrate Optimization for Complex Surface Milling Based on Predictive Modelling of Cutting Forces," Ph.D. thesis, Huazhong University of Science and Technology, Hubei Province, China.

[23] Kesriklioglu, S., Morrow, J. D., and Pfefferkorn, F. E., 2018, "Tool-Chip Interface Temperature Measurement in Interrupted and Continuous Oblique Cutting," ASME J. Manuf. Sci. Eng., 140(5), p. 051013.

[24] Adibi-Sedeh, A. H., Madhavan, V., and Bahr, B., 2003, "Extension of Oxleys Analysis of Machining to Use Different Material Models," ASME J. Manuf. Sci. Eng., 125(4), pp. 656-666. 